\title{
A Triangular Plate Bending Element Based on Discrete Kirchhoff Theory with Simple Explicit Expression
}

\author{
Longgang Tian ${ }^{1,2, * \mathbb{D}}$ and Ziling Cheng ${ }^{3}$ \\ 1 School of Civil Engineering, Southeast University, Nanjing 211189, China \\ 2 Institute of Future Underground Space, Southeast University, Nanjing 211189, China \\ 3 Southeast University-Monash University Joint Graduate School, Suzhou 215123, China; \\ 220184219@seu.edu.cn \\ * Correspondence: lgtian@seu.edu.cn
}

Citation: Tian, L.; Cheng, Z. A Triangular Plate Bending Element Based on Discrete Kirchhoff Theory with Simple Explicit Expression. Mathematics 2021, 9, 1181. https:// doi.org/10.3390/math9111181

Academic Editor: Michael Booty

Received: 21 April 2021

Accepted: 21 May 2021

Published: 24 May 2021

Publisher's Note: MDPI stays neutral with regard to jurisdictional claims in published maps and institutional affiliations.

Copyright: (c) 2021 by the authors. Licensee MDPI, Basel, Switzerland. This article is an open access article distributed under the terms and conditions of the Creative Commons Attribution (CC BY) license (https:/ / creativecommons.org/licenses/by/ $4.0 /)$.

\begin{abstract}
A Simple three-node Discrete Kirchhoff Triangular (SDKT) plate bending element is proposed in this study to overcome some inherent difficulties and provide efficient and dependable solutions in engineering practice for thin plate structure analyses. Different from the popular DKT (Discrete Kirchhoff Theory) triangular element, using the compatible trial function for the transverse displacement along the element sides, the construction of the present SDKT element is based on a specially designed trial function for the transverse displacement over the element, which satisfies interpolation conditions for the transverse displacements and the rotations at the three corner nodes. Numerical investigations of thin plate structures were conducted, using the proposed SDKT element. The results were compared with those by other prevalent plate elements, including the analytical solutions. It was shown that the present element has the simplest explicit expression of the nine-DOF (Degree of Freedom) triangular plate bending elements currently available that can pass the patch test. The numerical examples indicate that the present element has a good convergence rate and possesses high precision.
\end{abstract}

Keywords: triangular element; thin plate; patch test; Discrete Kirchhoff Theory; nine Degrees of Freedom

\section{Introduction}

Plate and shell structures have played significant roles in mechanical, civil, aerospace and naval engineering for the past several decades. Much effort has been made to study the finite elements of plate and shell structures with high performance and simple formulation [1,2]. Researchers have made great efforts to overcome the difficulty of the C1 continuity requirement for the analysis of thin plate structures. A large number of triangular plate bending elements have been proposed over the past several decades, including the first compatible triangular element HCT [3], the non-conforming and conforming element BCIZ [4-6], the very popular discrete Kirchhoff element DKT [7-9], the free formulation element T3A [10], hybrid/mixed elements [11-14], generalized conforming elements [15] and the C1-continuity triangular plate element [16]. Most of these elements possess high accuracy and versatility and have been successfully applied to linear or nonlinear analyses of various plate/shell structures $[17,18]$. In order to overcome the difficulties of the C1 continuity requirement, the Mindlin-Reissner plate theory was proposed for thin and thick plates $[19,20]$, which only required C0 continuity for the displacement functions of the element. However, due to the so-called shear locking phenomenon, these MindlinReissner plate elements usually led to poor results for the analysis of thin plates [21]. Many efforts have been made to eliminate the shear locking phenomenon, such as the assumed natural stain approach, the reduced integration approach, mixed/hybrid stress elements and assumed stress elements. The reduced integration approach was developed by Zienkiewicz et al. [22] and Pugh et al. [23]. The selective integration method was 
also employed for plate and shell analyses [24,25]. Bathe and Dvorkin [26] proposed the MITC family, and Nguyen et al. [27] developed the MISC element. Other popular plate elements also include the assumed stress/strain elements by Lee and Pian [28], Katili [29] and Brasile [30]; the RDKTM by Chen and Cheung [17]; and the DST family by Batoz and Katili [31], and Batoz and Lardeur [32]. Most of these elements for thick plates can avoid the shear locking phenomenon, but they usually need very complicated formulations and, thus, bring a lot of difficulties and computational cost for the programming of the elements.

Among all of the abovementioned triangular plate bending elements, the most prevalent elements are the BCIZ and DKT. The BCIZ element developed by Bazeley et al. [4] is the simplest of the above-mentioned elements. However, it is well known that the BCIZ fails to pass the patch test due to its incompatibility. Compatible BCIZ elements were developed by Razzaque [5] and Cheung and Chen [6], but they are rarely used due to the complex formulation. The DKT element is one of the most reliable and efficient plate-bending elements, but the complicated implementation and the complex explicit expression [8] hinder the widespread use of the DKT element, to a certain extent.

In this paper, a Simple, three-node, Discrete Kirchhoff Triangular (SDKT) plate bending element is proposed to overcome the abovementioned difficulties of the existing plate elements and provide efficient and dependable solutions for the analyses with plate elements. It will be shown in the following sections that the SDKT is the simplest of the nine-DOF triangular plate bending elements currently available that can pass the patch test, has a good convergence rate and possesses high precision.

\section{Displacement Function of the SDKT Element}

\subsection{Transverse Displacement Function of the Element}

In order to start the formulation of the SDKT element, first we consider the triangular element as shown in Figure 1. In Figure 1a, the triangle with only three corner nodes is used for interpolation of the transverse displacement over the element; in Figure 1b, the triangle has six nodes, including three corner nodes and three mid-side nodes, which are used for interpolation of the rotation over the element.

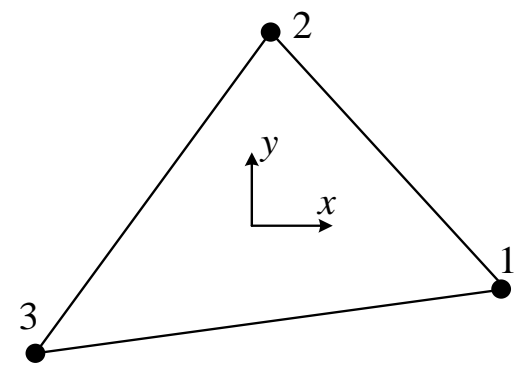

(a)

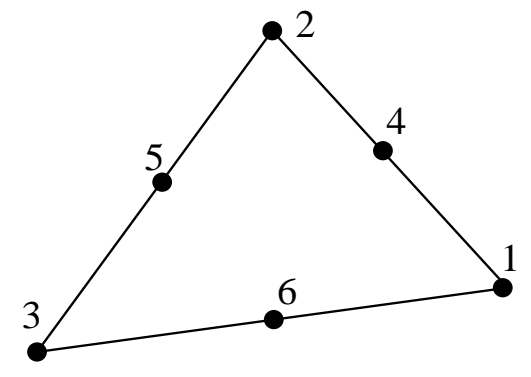

(b)

Figure 1. Triangular SDKT element: (a) Three-node element for the transverse displacement; (b) sixnode element for the rotation.

The trial functions for transverse displacement $w$, in each element, are assumed as follows:

$$
w=\sum_{i=1}^{3} L_{i}\left[d_{1 i}+\frac{1}{2}\left(y-y_{i}\right) d_{2 i}-\frac{1}{2}\left(x-x_{i}\right) d_{3 i}\right]
$$

where $L_{i}$ are the area coordinates of the three-node triangular element in the common finite element analysis, and $d_{1 i}, d_{2 i}$ and $d_{3 i}$ are the generalized DOFs of the nodes $i, \mathbf{x}_{i}=\left(x_{i}, y_{i}\right)$ which are the coordinates of the nodes $i . L_{i}$ can be expressed as follows:

$$
L_{i}=\frac{1}{2 A}\left(a_{i}+b_{i} x+c_{i} y\right)
$$




$$
a_{i}=x_{j} y_{m}-x_{m} y_{j}, b_{i}=y_{j}-y_{m}, c_{i}=-x_{j}+x_{m}
$$

where $A$ is the area of the triangular element, and $i=1,2,3 ; j=2,3,1 ; m=3,1,2$.

By using Equation (2), Equation (1) can be rewritten as follows:

$$
\begin{aligned}
w & =\frac{1}{2 A} \sum_{i=1}^{3}\left\{\left(a_{i}+b_{i} x+c_{i} y\right)\left[d_{1 i}+\frac{1}{2}\left(y-y_{i}\right) d_{2 i}-\frac{1}{2}\left(x-x_{i}\right) d_{3 i}\right]\right\} \\
& =\beta_{1}+\beta_{2} x+\beta_{3} y+\beta_{4} x y+\beta_{5} x^{2}+\beta_{6} y^{2}
\end{aligned}
$$

where

$$
\begin{aligned}
& \beta_{1}=\frac{1}{2 A} \sum_{i=1}^{3}\left(a_{i} d_{1 i}+\frac{1}{2} a_{i} d_{3 i} x_{i}-\frac{1}{2} a_{i} d_{2 i} y_{i}\right) \\
& \beta_{2}=\frac{1}{4 A} \sum_{i=1}^{3}\left(-a_{i} d_{3 i}+b_{i} d_{3 i} x_{i}-b_{i} d_{2 i} y_{i}+2 b_{i} d_{1 i}\right) \\
& \beta_{3}=\frac{1}{4 A} \sum_{i=1}^{3}\left(a_{i} d_{2 i}+c_{i} d_{3 i} x_{i}-c_{i} d_{2 i} y_{i}+2 c_{i} d_{1 i}\right) \\
& \beta_{4}=\frac{1}{4 A} \sum_{i=1}^{3}\left(b_{i} d_{2 i}-c_{i} d_{3 i}\right) \\
& \beta_{5}=-\frac{1}{4 A} \sum_{i=1}^{3}\left(b_{i} d_{3 i}\right) \\
& \beta_{6}=\frac{1}{4 A} \sum_{i=1}^{3}\left(c_{i} d_{2 i}\right)
\end{aligned}
$$

Here, we select the following:

$$
d_{1 i}=w_{i}=\left.w\right|_{\mathbf{x}=\mathbf{x}_{i}{ }^{\prime}} d_{2 i}=\theta_{x i}=\left.\frac{\partial w}{\partial y}\right|_{\mathbf{x}=\mathbf{x}_{i}}, d_{3 i}=\theta_{y i}=-\left.\frac{\partial w}{\partial x}\right|_{\mathbf{x}=\mathbf{x}_{i}}
$$

Substituting Equation (4) into Equation (6), we have the following:

$$
\begin{aligned}
& d_{1 i}=\beta_{1}+\beta_{2} x_{i}+\beta_{3} y_{i}+\beta_{4} x_{i} y_{i}+\beta_{5} x_{i}^{2}+\beta_{6} y_{i}^{2} \\
& d_{2 i}=\beta_{3}+\beta_{4} x_{i}+2 \beta_{6} y_{i} \\
& d_{3 i}=-\beta_{2}-\beta_{4} y_{i}-2 \beta_{5} x_{i}
\end{aligned}
$$

Substituting Equation (7) into Equation (1) and using $\sum_{i=1}^{3} L_{i}=1, \sum_{i=1}^{3} L_{i} x_{i}=x$ and $\sum_{i=1}^{3} L_{i} y_{i}=y$, we have the following:

$$
\begin{aligned}
w & =\sum_{i=1}^{3} L_{i}\left[\beta_{1}+\beta_{2} x_{i}+\beta_{3} y_{i}+\beta_{4} x_{i} y_{i}+\beta_{5} x_{i}^{2}+\beta_{6} y_{i}^{2}\right. \\
& \left.+\frac{1}{2}\left(y-y_{i}\right)\left(\beta_{3}+\beta_{4} x_{i}+2 \beta_{6} y_{i}\right)+\frac{1}{2}\left(x-x_{i}\right)\left(\beta_{2}+\beta_{4} y_{i}+2 \beta_{5} x_{i}\right)\right] \\
& \equiv \beta_{1}+\beta_{2} x+\beta_{3} y+\beta_{4} x y+\beta_{5} x^{2}+\beta_{6} y^{2}
\end{aligned}
$$

From Equations (1), (4), (6) and (8), we can conclude that the following transverse displacements,

$$
w=\sum_{i=1}^{3} L_{i}\left[w_{i}+\frac{1}{2}\left(y-y_{i}\right) \theta_{x i}-\frac{1}{2}\left(x-x_{i}\right) \theta_{y i}\right]
$$

satisfy the condition,

$$
w w_{i}=\left.w\right|_{\mathbf{x}=\mathbf{x}_{i}} \theta_{x i}=\left.\frac{\partial w}{\partial y}\right|_{\mathbf{x}=\mathbf{x}_{i}}, \theta_{y i}=-\left.\frac{\partial w}{\partial x}\right|_{\mathbf{x}=\mathbf{x}_{i}}
$$

at the three corner nodes. 


\subsection{The Kirchhoff Hypothesis}

By using Equation (9), the displacements of the SDKT element are defined as follows:

$$
\begin{aligned}
w & =\sum_{i=1}^{3}\left(\varphi_{i} w_{i}+\varphi_{x i} \theta_{x i}+\varphi_{y i} \theta_{y i}\right) \\
\theta_{x} & =\sum_{j=1}^{6} N_{j} \theta_{x j} \\
\theta_{y} & =\sum_{j=1}^{6} N_{j} \theta_{y j}
\end{aligned}
$$

where $N_{j}$ are the shape functions of the six-node triangular element in Figure $1 \mathrm{~b}$.

$$
\begin{gathered}
\varphi_{i}=L_{i}, \varphi_{x i}=\frac{1}{2}\left(y-y_{i}\right) L_{i}, \varphi_{y i}=-\frac{1}{2}\left(x-x_{i}\right) L_{i} \\
N_{j}=\left(2 L_{j}-1\right) L_{j}(j=1,2,3) \\
N_{4}=4 L_{1} L_{2}, N_{5}=4 L_{2} L_{3}, N_{6}=4 L_{3} L_{1}
\end{gathered}
$$

The Kirchhoff hypothesis of the present element is imposed at the following:

(a) The corner nodes in Figure 1a,

$$
\theta_{x i}=\left.\frac{\partial w}{\partial y}\right|_{\mathbf{x}=\mathbf{x}_{i}}, \theta_{y i}=-\left.\frac{\partial w}{\partial x}\right|_{\mathbf{x}=\mathbf{x}_{i}} \text { at nodes } i(i=1,2,3)
$$

(b) The mid-side nodes in Figure 1b,

$$
\theta_{x k}=\left.\frac{\partial w}{\partial y}\right|_{\mathbf{x}=\mathbf{x}_{k}}, \theta_{y k}=-\left.\frac{\partial w}{\partial x}\right|_{\mathbf{x}=\mathbf{x}_{k}} \text { at nodes } k(k=4,5,6)
$$

The Kirchhoff condition in Equation (14) at the corner nodes is naturally satisfied in Equation (11) of the transverse displacement function $w$.

Substituting Equation (11) into Equation (15), we have the following:

$$
\begin{aligned}
& \theta_{x k}=\sum_{i=1}^{3}\left(\varphi_{i, y} w_{i}+\varphi_{x i, y}^{k} \theta_{x i}+\varphi_{y i, y}^{k} \theta_{y i}\right) \\
& \theta_{y k}=-\sum_{i=1}^{3}\left(\varphi_{i, x} w_{i}+\varphi_{x i, x}^{k} \theta_{x i}+\varphi_{y i, x}^{k} \theta_{y i}\right) \\
& (k=4,5,6)
\end{aligned}
$$

where

$$
\begin{aligned}
& \varphi_{i, y}=L_{i, y}, \varphi_{x i, y}^{k}=\frac{1}{2}\left[L_{i}\left(\mathbf{x}_{k}\right)+\left(y_{k}-y_{i}\right) L_{i, y}\right], \varphi_{y i, y}^{k}=-\frac{1}{2}\left(x_{k}-x_{i}\right) L_{i, y} \\
& \varphi_{i, x}=L_{i, x}, \varphi_{x i, x}^{k}=\frac{1}{2}\left(y_{k}-y_{i}\right) L_{i, x}, \varphi_{y i, x}^{k}=-\frac{1}{2}\left[L_{i}\left(\mathbf{x}_{k}\right)+\left(x_{k}-x_{i}\right) L_{i, x}\right]
\end{aligned}
$$

\subsection{Displacement Function of the Element}

Substituting Equation (16) into Equation (11), the surplus parameters $\theta_{x k}$ and $\theta_{y k}$ at the mid-side nodes $k(k=4,5,6)$ in Figure $1 \mathrm{~b}$ can be finally eliminated:

$$
\begin{aligned}
& \theta_{x}=\sum_{i=1}^{3} N_{i} \theta_{x i}+\sum_{k=4}^{6} N_{k} \theta_{x k}=\sum_{i=1}^{3}\left(R_{i} w_{i}+R_{x i} \theta_{x i}+R_{y i} \theta_{y i}\right) \\
& \theta_{y}=\sum_{i=1}^{3} N_{i} \theta_{y i}+\sum_{k=4}^{6} N_{k} \theta_{y k}=\sum_{i=1}^{3}\left(Q_{i} w_{i}+Q_{x i} \theta_{x i}+Q_{y i} \theta_{y i}\right)
\end{aligned}
$$


where

$$
\begin{aligned}
& R_{i}=\left(\sum_{k=4}^{6} N_{k}\right) \varphi_{i, y}, R_{x i}=N_{i}+\sum_{k=4}^{6}\left(N_{k} \varphi_{x i, y}^{k}\right), R_{y i}=\sum_{k=4}^{6}\left(N_{k} \varphi_{y i, y}^{k}\right) \\
& Q_{i}=-\left(\sum_{k=4}^{6} N_{k}\right) \varphi_{i, x}, Q_{x i}=-\sum_{k=4}^{6}\left(N_{k} \varphi_{x i, x}^{k}\right), Q_{y i}=N_{i}-\sum_{k=4}^{6}\left(N_{k} \varphi_{y i, x}^{k}\right)
\end{aligned}
$$

Finally, the displacement trial function of the SDKT element can be expressed as follows:

$$
\left\{\begin{array}{l}
w \\
\theta_{x} \\
\theta_{y}
\end{array}\right\}=\tilde{\mathbf{N}} \mathbf{a}^{e}=\left[\begin{array}{lll}
\tilde{\mathbf{N}}_{1} & \tilde{\mathbf{N}}_{2} & \tilde{\mathbf{N}}_{3}
\end{array}\right]\left\{\begin{array}{l}
\mathbf{a}_{1} \\
\mathbf{a}_{2} \\
\mathbf{a}_{3}
\end{array}\right\}
$$

where

$$
\tilde{\mathbf{N}}_{i}=\left[\begin{array}{ccc}
\varphi_{i} & \varphi_{x i} & \varphi_{y i} \\
R_{i} & R_{x i} & R_{y i} \\
Q_{i} & Q_{x i} & Q_{y i}
\end{array}\right], \mathbf{a}_{i}=\left\{\begin{array}{c}
w_{i} \\
\theta_{x i} \\
\theta_{y i}
\end{array}\right\}(i=1,2,3)
$$

where $\left(\phi_{i}, \phi_{x i}, \phi_{y i}\right)$ are defined in Equation (12), and $\left(R_{i}, R_{x i}, R_{y i}\right)$ and $\left(Q_{i}, Q_{x i}, Q_{y i}\right)$ are defined in Equation (19). We can see that the explicit expression and implementation of the SDKT element in Equation (20) are much simpler than the existing nine-DOF triangular plate elements, passing the patch test.

\section{Stiffness Matrix of the SDKT Element}

By using the displacement function in Equation (20), the stiffness matrix of the SDKT element for thin plates based on Kirchhoff theory can be written as follows:

$$
\mathbf{K}^{e}=\int_{\Omega^{e}} \mathbf{B}^{\mathrm{T}} \mathbf{D}_{b} \mathbf{B} d x d y
$$

where

$$
\begin{gathered}
\mathbf{B}=\left[\begin{array}{ccc}
\mathbf{B}_{1} & \mathbf{B}_{2} & \mathbf{B}_{3}
\end{array}\right] \\
\mathbf{B}_{i}=\left[\begin{array}{ccc}
Q_{i, x} & Q_{x i, x} & Q_{y i, x} \\
-R_{i, y} & -R_{x i, y} & -R_{y i, y} \\
Q_{i, y}-R_{i, x} & Q_{x i, y}-R_{x i, x} & Q_{y i, y}-R_{y i, x}
\end{array}\right](i=1,2,3) \\
\mathbf{D}_{b}=D\left[\begin{array}{ccc}
1 & v & 0 \\
v & 1 & 0 \\
0 & 0 & (1-v) / 2
\end{array}\right]
\end{gathered}
$$

where $D=\frac{E h^{3}}{12\left(1-v^{2}\right)}$. E is the elastic modulus, $v$ is the Poisson's ratio and $h$ represents the thickness of the plate.

\section{Comparison with the DKT Element}

\subsection{The Brief Formulation of DKT Element}

The derivation and formulation of DKT element can be found in the paper by Batoz, Bathe and Ho [8]. They are briefly listed here to compare with the above proposed SDKT element.

As shown in Figure 2, the derivatives of the transverse displacement $w$ of a triangular plate element around the two independent axes are defined as follows:

$$
\theta_{x}=\frac{\partial w}{\partial x}, \theta_{y}=\frac{\partial w}{\partial y}
$$




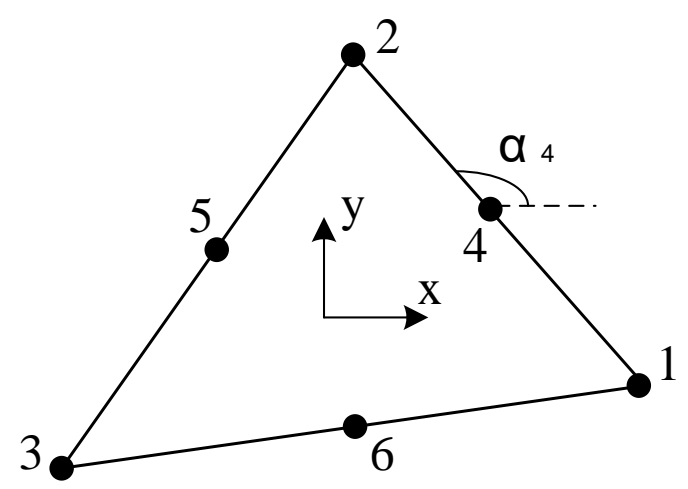

Figure 2. The triangular element for DKT.

The Kirchhoff hypotheses are presented in the following discrete way:

(a) At the corner nodes i,

$$
\theta_{x i}=\left.\frac{\partial w}{\partial x}\right|_{\mathbf{x}=\mathbf{x}_{i}}, \theta_{y i}=\left.\frac{\partial w}{\partial y}\right|_{\mathbf{x}=\mathbf{x}_{i}}(i=1,2,3)
$$

(b) At the mid-side nodes $k$,

$$
\begin{aligned}
& \theta_{n k}=\frac{1}{2}\left(\theta_{n i}+\theta_{n j}\right) \\
& \theta_{s k}=\left.\frac{\partial w}{\partial s}\right|_{\mathbf{x}=\mathbf{x}_{k}}=\frac{1.5}{l_{k}}\left(w_{j}-w_{i}\right)-\frac{1}{4}\left(\theta_{s i}+\theta_{s j}\right) \\
& (k=4,5,6)
\end{aligned}
$$

where $\mathbf{x}_{i}=\left(x_{i}, y_{i}\right)$ are the coordinates of the nodes $i ; l_{k}$ represents the length of the element side $i j ; s$ and $n$ indicate the tangent and normal direction of the element side $i j$, respectively; and $i=1,2,3$ and $j=2,3,1$ when $k=4,5,6$.

Along the element side $i j$,

$$
\left\{\begin{array}{c}
\theta_{s k} \\
\theta_{n k}
\end{array}\right\}=\left[\begin{array}{cc}
\cos \alpha_{k} & \sin \alpha_{k} \\
-\sin \alpha_{k} & \cos \alpha_{k}
\end{array}\right]\left\{\begin{array}{c}
\theta_{x k} \\
\theta_{y k}
\end{array}\right\}(k=4,5,6)
$$

The rotations $\theta_{x}$ and $\theta_{y}$ are defined as follows:

$$
\begin{aligned}
& \theta_{x}=\sum_{i=1}^{6} N_{i} \theta_{x i} \\
& \theta_{y}=\sum_{i=1}^{6} N_{i} \theta_{y i}
\end{aligned}
$$

where

$$
\begin{aligned}
& N_{i}=\left(2 L_{i}-1\right) L_{i}(i=1,2,3) \\
& N_{4}=4 L_{1} L_{2}, N_{5}=4 L_{2} L_{3}, N_{6}=4 L_{3} L_{1}
\end{aligned}
$$

The expressions of $L_{i}$ are the same as those in Equations (2) and (3).

By using Equations (27) to (30), the displacements of the DKT element are obtained as follows:

$$
\begin{aligned}
& \theta_{x}=\sum_{i=1}^{3}\left(D_{i} w_{i}+D_{x i} \theta_{x i}+D_{y i} \theta_{y i}\right) \\
& \theta_{y}=\sum_{i=1}^{3}\left(H_{i} w_{i}+H_{x i} \theta_{x i}+H_{y i} \theta_{y i}\right)
\end{aligned}
$$


where

$$
\begin{aligned}
& D_{1}=1.5\left(\frac{m_{6} N_{6}}{l_{6}}-\frac{m_{4} N_{4}}{l_{4}}\right), \\
& D_{2}=1.5\left(\frac{m_{4} N_{4}}{l_{4}}-\frac{m_{5} N_{5}}{l_{5}}\right), \\
& D_{3}=1.5\left(\frac{m_{5} N_{5}}{l_{5}}-\frac{m_{6} N_{6}}{l_{6}}\right), \\
& D_{x 1}=N_{1}+N_{4}\left(0.5 n_{4}^{2}-0.25 m_{4}^{2}\right)+N_{6}\left(0.5 n_{6}^{2}-0.25 m_{6}^{2}\right), \\
& D_{x 2}=N_{2}+N_{4}\left(0.5 n_{4}^{2}-0.25 m_{4}^{2}\right)+N_{5}\left(0.5 n_{5}^{2}-0.25 m_{5}^{2}\right), \\
& D_{x 3}=N_{3}+N_{5}\left(0.5 n_{5}^{2}-0.25 m_{5}^{2}\right)+N_{6}\left(0.5 n_{6}^{2}-0.25 m_{6}^{2}\right), \\
& D_{y 1}=-0.75\left(m_{4} n_{4} N_{4}+m_{6} n_{6} N_{6}\right), \\
& D_{y 2}=-0.75\left(m_{4} n_{4} N_{4}+m_{5} n_{5} N_{5}\right), \\
& D_{y 3}=-0.75\left(m_{5} n_{5} N_{5}+m_{6} n_{6} N_{6}\right) \\
& H_{1}=1.5\left(\frac{n_{6} N_{6}}{l_{6}}-\frac{n_{4} N_{4}}{l_{4}}\right), \\
& H_{2}=1.5\left(\frac{n_{4} N_{4}}{l_{4}}-\frac{n_{5} N_{5}}{l_{5}}\right), \\
& H_{3}=1.5\left(\frac{n_{5} N_{5}}{l_{5}}-\frac{n_{6} N_{6}}{l_{6}}\right), \\
& H_{x 1}=-0.75\left(m_{4} n_{4} N_{4}+m_{6} n_{6} N_{6}\right), \\
& H_{x 2}=-0.75\left(m_{4} n_{4} N_{4}+m_{5} n_{5} N_{5}\right), \\
& H_{x 3}=-0.75\left(m_{5} n_{5} N_{5}+m_{6} n_{6} N_{6}\right), \\
& H_{y 1}=N_{1}+N_{4}\left(0.5 m_{4}^{2}-0.25 n_{4}^{2}\right)+N_{6}\left(0.5 m_{6}^{2}-0.25 n_{6}^{2}\right), \\
& H_{y 2}=N_{2}+N_{4}\left(0.5 m_{4}^{2}-0.25 n_{4}^{2}\right)+N_{5}\left(0.5 m_{5}^{2}-0.25 n_{5}^{2}\right), \\
& H_{y 3}=N_{3}+N_{5}\left(0.5 m_{5}^{2}-0.25 n_{5}^{2}\right)+N_{6}\left(0.5 m_{6}^{2}-0.25 n_{6}^{2}\right)
\end{aligned}
$$

and

$$
m_{k}=\cos \alpha_{k}, n_{k}=\sin \alpha_{k}(k=4,5,6)
$$

The subsequent procedure to obtain the stiffness matrix of DKT element is similar with that of the SDKT element, as shown in Section 3.

\subsection{Some Comments on SDKT Element}

In Section 4.1, the formulations of the displacement function of the popular DKT element are listed very briefly. As compared with those of the SDKT element in Section 2.3, we can see that the formulations for the proposed SDKT element are much simpler. Moreover, it is very easy and convenient to incorporate the SDKT element in a finite element program. Numerical examples in the next section will also demonstrate the fine performances of this element.

\section{Numerical Examples}

\subsection{Patch Test}

For the proposed SDKT element, its stiffness matrix should pass the patch test to produce dependable results. Here, the patch test suggested by Katili [29], and Batoz and Katili [31] is employed to check the performance of the current SDKT element.

A plate with an arbitrary mesh is shown in Figure 3. The thickness of the plate is $h=0.01$, and the material properties of the plate are $E=10^{7}$ and $v=0.3$. The patch test is performed by enforcing the following boundary conditions:

$$
w=x^{2}+x y+y^{2}, \theta_{x}=x+2 y, \theta_{y}=-(2 x+y)
$$




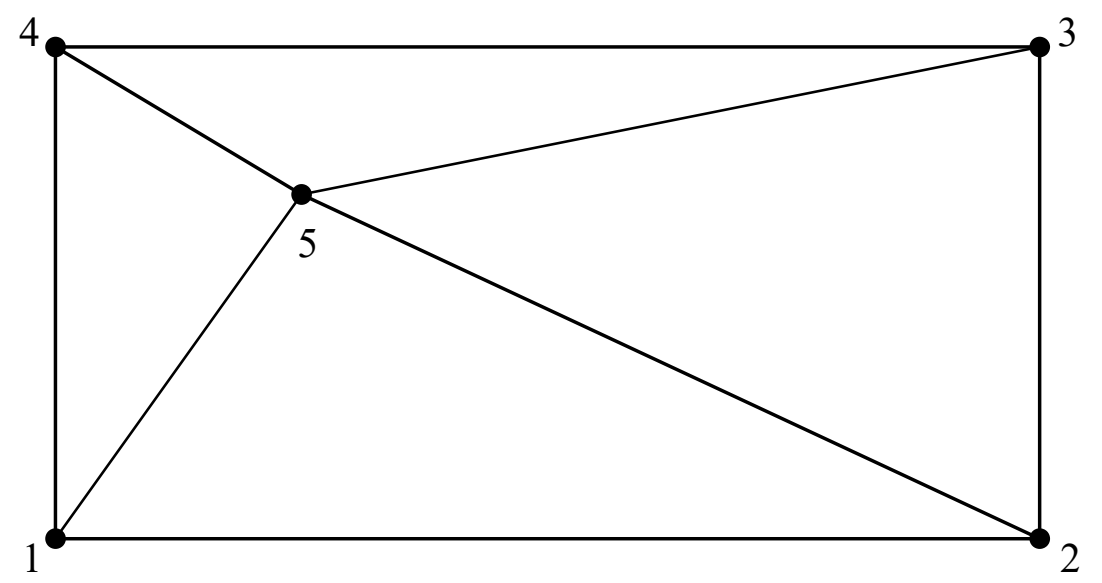

Node coordinates

$1(0.0,0.0)$

$2(2.0,0.0)$

$3(2.0,1.0)$

$4(0.0,1.0)$

$5(0.5,0.7)$

Figure 3. Mesh of the plate for the patch test.

The numerical results are listed in Table 1, which illustrate that the present SDKT element passed the patch test, while the BCIZ element failed to pass the patch test.

Table 1. Patch test results of the different plate elements.

\begin{tabular}{ccccccc}
\hline \multirow{2}{*}{ Element } & \multicolumn{3}{c}{ Displacement at Node 5} & \multicolumn{3}{c}{ Moment in the Element } \\
\cline { 2 - 6 } & $\boldsymbol{w}_{5}$ & $\boldsymbol{\theta}_{\boldsymbol{x} 5}$ & $\boldsymbol{\theta}_{\boldsymbol{y} \mathbf{5}}$ & $\boldsymbol{M}_{\boldsymbol{x}}$ & $\boldsymbol{M}_{\boldsymbol{y}}$ & $\boldsymbol{M}_{\boldsymbol{x} \boldsymbol{y}}$ \\
\hline BCIZ & 1.049 & 1.95 & -1.63 & \multicolumn{2}{c}{ No constant moment state } \\
DKT & 1.090 & 1.90 & -1.70 & -2.381 & -2.381 & -0.641 \\
SDKT & 1.090 & 1.90 & -1.70 & -2.381 & -2.381 & -0.641 \\
Exact & 1.090 & 1.90 & -1.70 & -2.381 & -2.381 & -0.641 \\
\hline
\end{tabular}

\subsection{Square Plate under Uniform Load}

In this example, a simply supported or clamped square plate subjected to uniform surface load $q$ is considered. The length of the side of the square plate is $l$, and the thickness of the plate is $h$. The assumed material properties are $E=10^{7}$ and $v=0.3$. Only one quarter of the plate is modeled due to the double symmetry of the whole problem, which is shown in Figure 4. Figure 5 illustrates the central deflection of a simply supported and clamped square plate under uniform load when the mesh is $4 \times 4$ for one quarter of the plate, using the SDKT element.

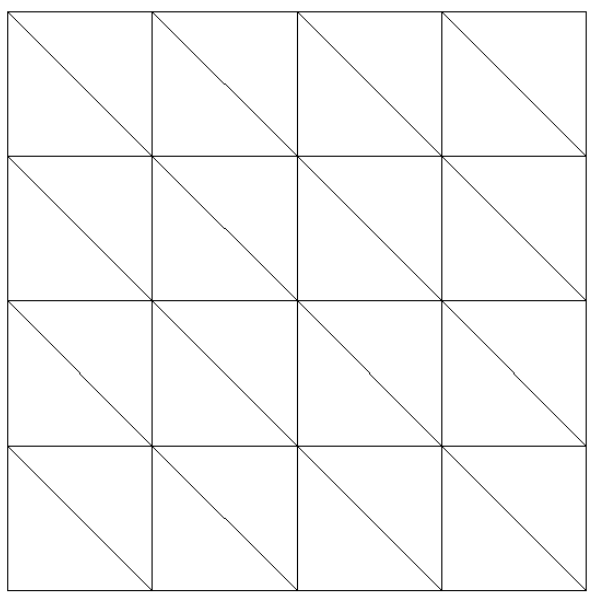

Figure 4. Mesh of one quarter of a square plate $(4 \times 4)$. 


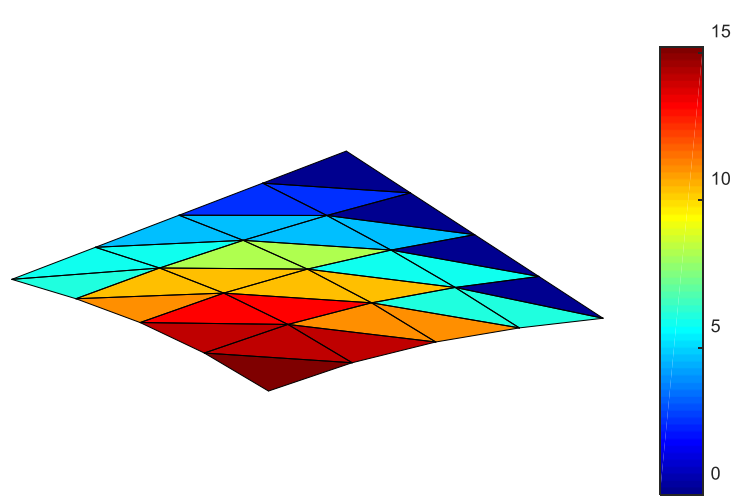

(a)

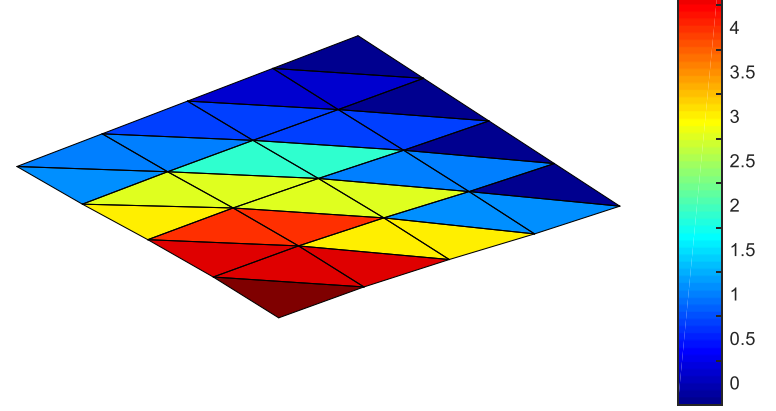

(b)

Figure 5. Central deflection for a square plate under uniform load using SDKT element: (a) Simply supported; (b) clamped.

Tables 2 and 3 list the results given by the BCIZ, DKT and SDKT, which are further illustrated in Figures 6 and 7 to show the convergence of these elements. It can be seen that when a very coarse mesh is used, i.e., $2 \times 2$ or $4 \times 4$, the residual error given by the SDKT is higher than other elements. However, when a dense mesh is used, such as $16 \times 16$ or $32 \times 32$, which is of acceptable computational cost in practice, the SDKT has almost the same accuracy as compared with the other elements. In substantial application, the SDKT is more favorable than the other two types of elements since it has a much simpler explicit expression and can be more easily incorporated in a finite element program.

Table 2. Central deflection for a simply supported square plate under uniform load.

\begin{tabular}{cccc}
\hline \multirow{2}{*}{ Mesh } & \multicolumn{3}{c}{ Element (Error) } \\
\cline { 2 - 4 } & BCIZ & DKT & SDKT \\
\hline $2 \times 2$ & $0.4123(1.5 \%)$ & $0.3673(-9.6 \%)$ & $0.4509(11.0 \%)$ \\
$4 \times 4$ & $0.4104(1.0 \%)$ & $0.3972(-2.2 \%)$ & $0.4197(3.3 \%)$ \\
$8 \times 8$ & $0.4087(0.6 \%)$ & $0.4040(-0.5 \%)$ & $0.4097(0.9 \%)$ \\
$16 \times 16$ & $0.4076(0.3 \%)$ & $0.4057(-0.1 \%)$ & $0.4071(0.2 \%)$ \\
$32 \times 32$ & $0.4069(0.2 \%)$ & $0.4061(0.0 \%)$ & $0.4064(0.0 \%)$ \\
Exact & & $0.4062\left(\times q l^{4} / 100 D\right)$ & \\
\hline
\end{tabular}

Table 3. Central deflection for a clamped square plate under uniform load.

\begin{tabular}{cccc}
\hline \multirow{2}{*}{ Mesh } & \multicolumn{3}{c}{ Element (Error) } \\
\cline { 2 - 4 } & BCIZ & DKT & SDKT \\
\hline $2 \times 2$ & $0.1270(0.4 \%)$ & $0.1212(-4.2 \%)$ & $0.1810(43.1 \%)$ \\
$4 \times 4$ & $0.1298(2.6 \%)$ & $0.1257(-0.6 \%)$ & $0.1463(15.7 \%)$ \\
$8 \times 8$ & $0.1280(1.2 \%)$ & $0.1263(-0.2 \%)$ & $0.1324(4.7 \%)$ \\
$16 \times 16$ & $0.1272(0.6 \%)$ & $0.1265(0.0 \%)$ & $0.1281(1.3 \%)$ \\
$32 \times 32$ & $0.1268(0.2 \%)$ & $0.1265(0.0 \%)$ & $0.1269(0.3 \%)$ \\
Exact & & $0.1265\left(\times q l^{4} / 100 D\right)$ & \\
\hline
\end{tabular}




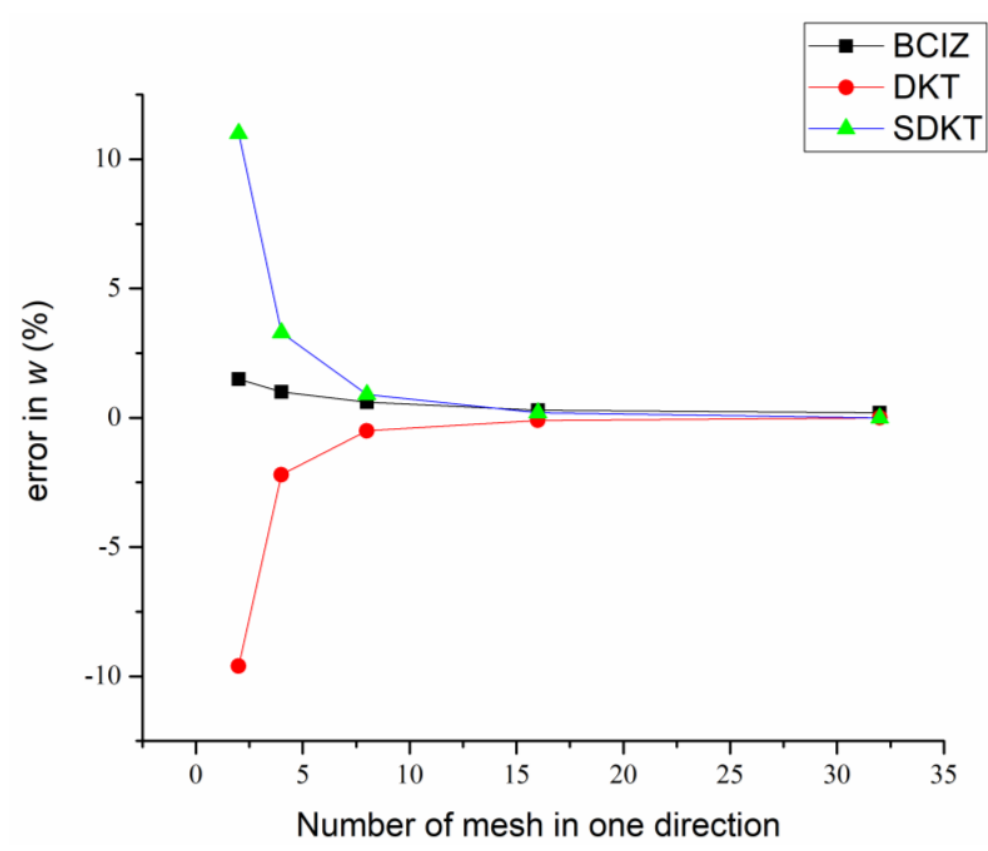

Figure 6. Error of the central deflection for a simply supported square plate under uniform load.

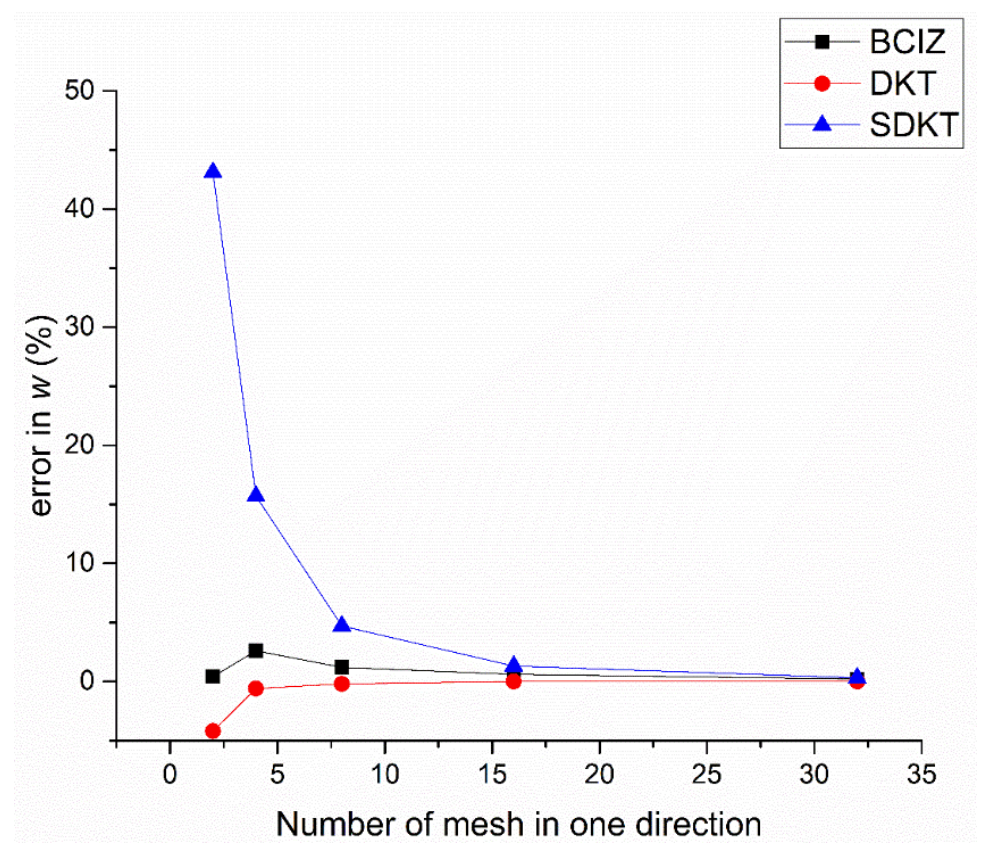

Figure 7. Error of the central deflection for a clamped square plate under uniform load.

\subsection{Square Plate under Point Load}

In this example, the same plate is used for the analysis, while the plate is loaded by a point load $p$ at its center. The length of the side of the square plate is $l$, and the thickness of the plate is $h$. The assumed material properties of the plate are $E=10^{7}$ and $v=0.3$. Only one quarter of the plate is modeled in the same way as shown in Figure 4 due to its double symmetry. Figure 8 shows the central deflection of a simply supported and clamped square plate under center point load when the mesh is $16 \times 16$ for one quarter of the plate, using the SDKT element. 


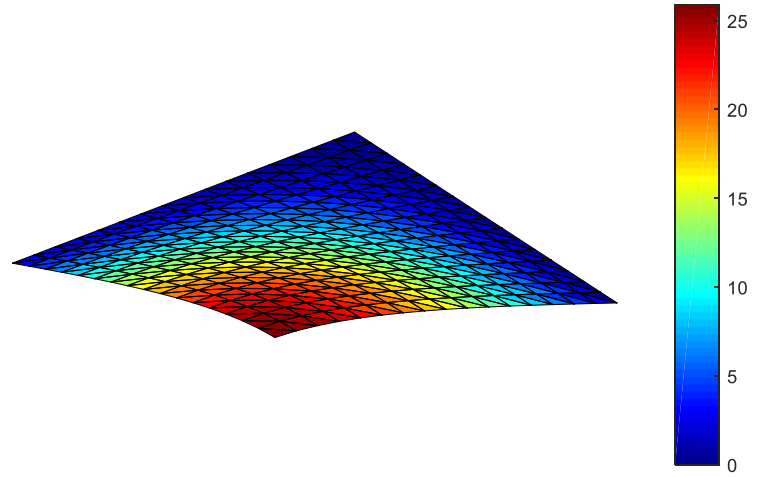

(a)

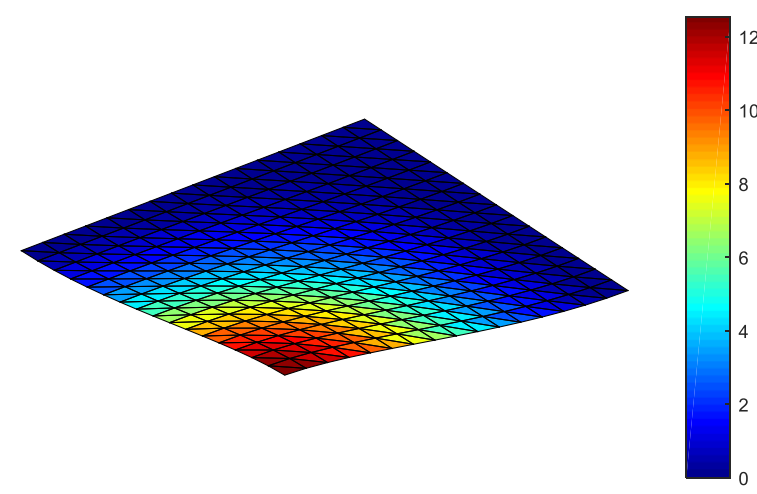

(b)

Figure 8. Central deflection for a square plate under center point load using SDKT element: (a) Simply supported; (b) clamped.

Tables 4 and 5 list the results given by the BCIZ, DKT and SDKT, which are further illustrated by Figures 9 and 10 to show the convergence of these elements. It can be seen that when a very coarse mesh is used, the residual error given by the SDKT is higher than other elements. However, when a dense mesh is used, which is of acceptable computational cost in practice, the SDKT has almost the same accuracy as compared with the other elements. All these results indicate the good accuracy and convergence rate of the present SDKT.

Table 4. Central deflection for a simply supported square plate under center point load.

\begin{tabular}{cccc}
\hline \multirow{2}{*}{ Mesh } & \multicolumn{3}{c}{ Element (Error) } \\
\cline { 2 - 4 } & BCIZ & DKT & SDKT \\
\hline $2 \times 2$ & $1.3715(18.2 \%)$ & $1.2820(10.5 \%)$ & $1.5929(37.3 \%)$ \\
$4 \times 4$ & $1.2418(7.1 \%)$ & $1.1993(3.4 \%)$ & $1.3010(12.2 \%)$ \\
$8 \times 8$ & $1.1927(2.8 \%)$ & $1.1719(1.0 \%)$ & $1.2031(3.7 \%)$ \\
$16 \times 16$ & $1.1734(1.2 \%)$ & $1.1635(0.3 \%)$ & $1.1728(1.1 \%)$ \\
$32 \times 32$ & $1.1657(0.5 \%)$ & $1.1611(0.1 \%)$ & $1.1637(0.3 \%)$ \\
Exact & & $1.160\left(\times p l^{2} / 100 D\right)$ & \\
\hline
\end{tabular}

Table 5. Central deflection for a clamped square plate under center point load.

\begin{tabular}{cccc}
\hline \multirow{2}{*}{ Mesh } & \multicolumn{3}{c}{ Element (Error) } \\
\cline { 2 - 4 } & BCIZ & DKT & SDKT \\
\hline $2 \times 2$ & $0.6531(16.4 \%)$ & $0.6342(13.0 \%)$ & $0.9275(65.3 \%)$ \\
$4 \times 4$ & $0.6118(9.0 \%)$ & $0.5905(5.2 \%)$ & $0.6939(23.6 \%)$ \\
$8 \times 8$ & $0.5829(3.9 \%)$ & $0.5706(1.7 \%)$ & $0.6038(7.6 \%)$ \\
$16 \times 16$ & $0.5703(1.6 \%)$ & $0.5640(0.5 \%)$ & $0.5740(2.3 \%)$ \\
$32 \times 32$ & $0.5650(0.7 \%)$ & $0.5620(0.1 \%)$ & $0.5649(0.7 \%)$ \\
Exact & & $0.5612\left(\times p l^{2} / 100 D\right)$ & \\
\hline
\end{tabular}




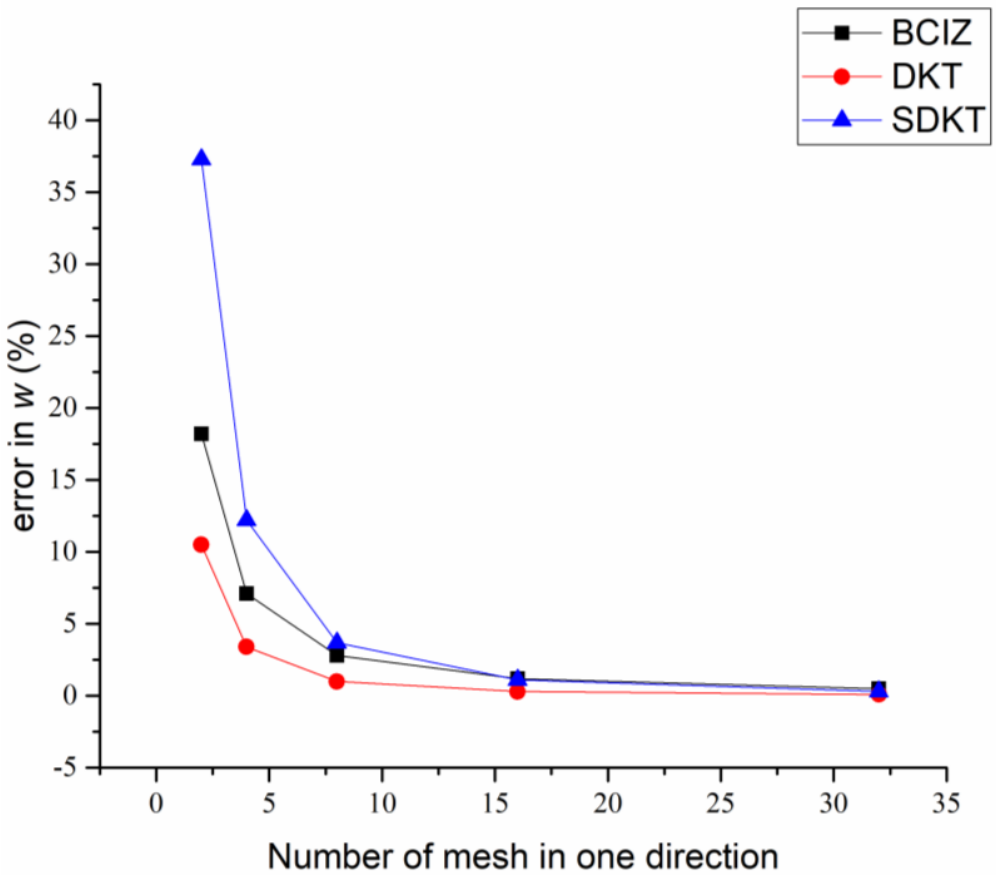

Figure 9. Error of the central deflection for a simply supported square plate under center point load.

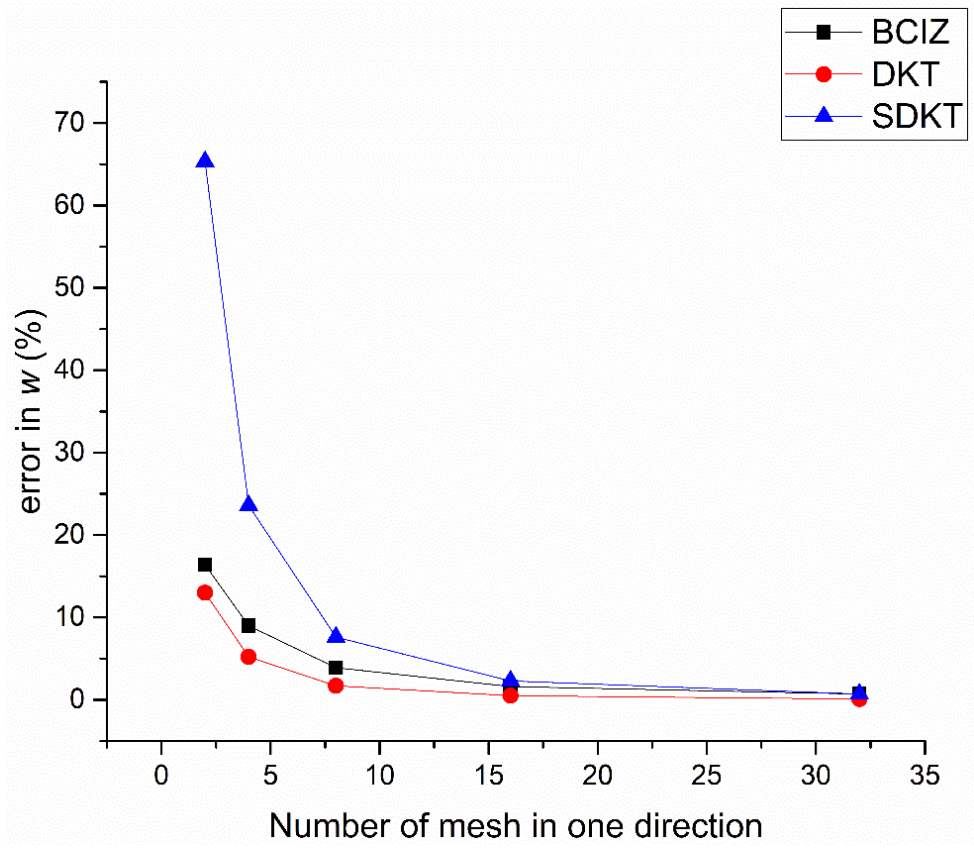

Figure 10. Error of the central deflection for a clamped square plate under center point load.

\subsection{Circular Plate under Uniform Load}

In this example, a clamped circular plate subjected to uniformly distributed load $q$ is studied. The thickness of the plate is $h=1$, and radius of the plate is $r=100$. The material properties of the plate are $E=10^{7}$ and $v=0.3$. Only one quarter of the plate is discretized as shown in Figure 11 due to the double symmetry property. Overall, dependable results are obtained for this problem with the SDKT element, as listed in Table 6 and shown in Figure 12. 


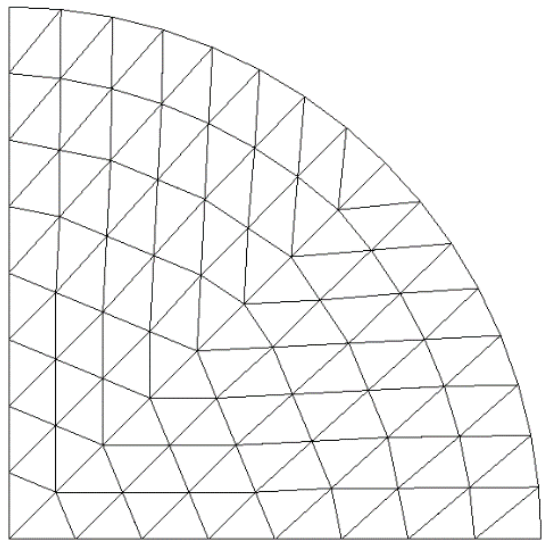

Figure 11. Mesh of one quarter of a clamped circular plate (81 nodes).

Table 6. Central deflection for a clamped circular plate under uniform load.

\begin{tabular}{cccc}
\hline \multirow{2}{*}{ Number of Nodes } & \multicolumn{3}{c}{ Element (Error) } \\
\cline { 2 - 4 } & BCIZ & DKT & SDKT \\
\hline 25 & $0.01619(3.6 \%)$ & $0.01613(3.2 \%)$ & $0.01933(23.7 \%)$ \\
81 & $0.01581(1.2 \%)$ & $0.01576(0.8 \%)$ & $0.01655(5.9 \%)$ \\
289 & $0.01570(0.4 \%)$ & $0.01566(0.2 \%)$ & $0.01586(1.5 \%)$ \\
1089 & $0.01566(0.2 \%)$ & $0.01563(0.0 \%)$ & $0.01568(0.3 \%)$ \\
Exact & & $0.01563\left(\times q R^{4} / 100 D\right)$ & \\
\hline
\end{tabular}

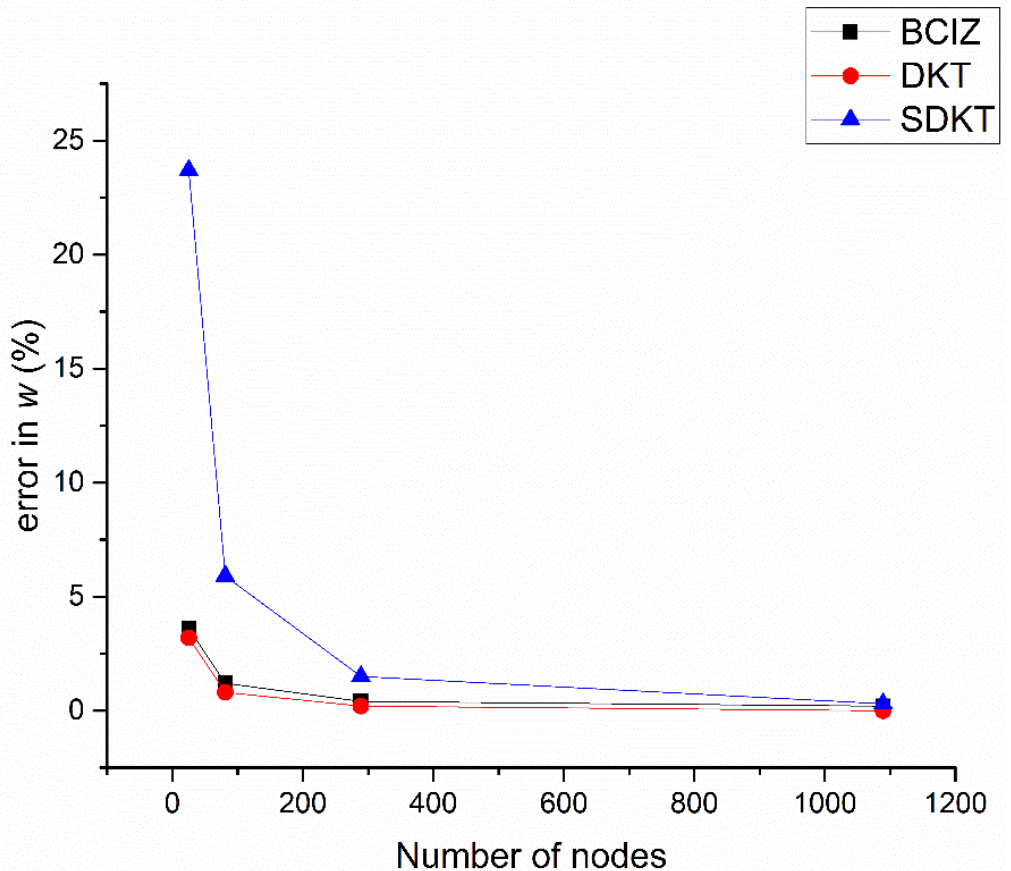

Figure 12. Error of central deflection for a clamped circular plate under uniform load.

\section{Conclusions}

In this paper, a new SDKT element is proposed for the analysis of thin plate structures, based on a specially designed trial function for the transverse displacement and the Discrete Kirchhoff Theory. The present SDKT element is a nine-DOF triangular plate bending element with very simple explicit expression, which can be easily incorporated in a finite element program. It is believed to be the simplest nine-DOF triangular plate bending element currently available that can pass the patch test. The formulations of the present 
SDKT element are compared with those of the DKT element to show its simplicity in formulation. In the numerical examples, the results by the SDKT element are also compared with the analytical solutions and results by other popular plate elements, demonstrating the overall good performance of the SDKT element.

The SDKT element proposed in this paper is a nine-DOF triangular plate bending element, which does not take the influence of the transverse shear deformation into account, so the present element can only be applied to thin plate structures, currently. To consider the influence of the transverse shear deformation, the displacement function of the plate element should be further studied and improved; shear-deformable plate elements are needed for thick to very thin plates, which will be our research topic in the future.

\begin{abstract}
Author Contributions: Conceptualization, L.T.; methodology, L.T.; software, Z.C.; data curation, Z.C.; writing-original draft preparation, L.T.; writing-review and editing, Z.C.; project administration, L.T.; funding acquisition, L.T. Both authors have read and agreed to the published version of the manuscript.

Funding: This research was funded by National Natural Science Foundation of China, grant number 51808114; Natural Science Foundation of Jiangsu Province, grant number BK20170670.
\end{abstract}

Conflicts of Interest: The authors declare no conflict of interest.

\title{
References
}

1. Iura, M.; Atluri, S.N. Advances in finite rotations in structural mechanics. CMES Comp. Model. Eng. 2003, 4, 213-216.

2. Gal, E.; Levy, R. Geometrically nonlinear analysis of shell structures using a flat triangular shell finite element. Arch. Comput. Methods Eng. 2006, 13, 331-388. [CrossRef]

3. Clough, R.W.; Tocher, J.L. Finite element stiffness matrices for analysis of plate bending. In Proceedings of the Conference on Matrix Methods in Structural Mechanics, Dayton, OH, USA, 26-28 October 1965; pp. 515-545.

4. Bazeley, G.P.; Cheung, Y.K.; Irons, B.M. Triangular elements in plate bending conforming and non-conforming solutions. In Proceedings of the Conference on Matrix Methods in Structural Mechanics, Dayton, OH, USA, 26-28 October 1965 ; pp. 547-576.

5. Razzaque, A. Program for triangular bending elements with derivative smoothing. Int. J. Numer. Methods Eng. $1973,6,333-343$. [CrossRef]

6. Cheung, Y.K.; Chen, W.J. Refined nine-parameter triangular thin plate bending element by using refined direct stiffness method. Int. J. Numer. Methods Eng. 1995, 38, 283-298. [CrossRef]

7. Stricklin, J.A.; Haisler, W.E.; Tisdale, P.R.; Gunderson, R. A rapidly converging triangular plate element. AIAA J. 1969, 7, $180-181$. [CrossRef]

8. Batoz, J.L.; Bathe, K.J.; Ho, L.W. A study of three-node triangular plate bending elements. Int. J. Numer. Methods Eng. 1980, 15, 1771-1812. [CrossRef]

9. Batoz, J.L. An explicit formulation for an efficient triangular plate-bending element. Int. J. Numer. Methods Eng. 1982, 18, 1077-1089. [CrossRef]

10. Felippa, C.A.; Bergan, P.G. A triangular bending element based on an energy-orthogonal free formulation. Comput. Methods Appl. Mech. Eng. 1987, 61, 129-160. [CrossRef]

11. Allman, D.J. Triangular finite element bending with constant and linearly varying bending elements. In Proceedings of the Symposium on High Speed Computing of Elastic Structures, Liege, Belgium, 23-28 August 1971; pp. 105-110.

12. Xu, Z. A simple and efficient triangular finite element for plate bending. Acta Mechnica Sin. 1986, 2, 185-192.

13. Maunder, E.A.W.; Almeida, J.P.M. A triangular hybrid equilibrium plate element of general degree. Int. J. Numer. Methods Eng. 2005, 63, 315-350. [CrossRef]

14. Choo, Y.S.; Choi, N.; Lee, B.C. A new hybrid-Trefftz triangular and quadrilateral plate elements. Appl. Math. Model. 2010, 34, 14-23. [CrossRef]

15. Long, Z.F. Generalized conforming triangular elements for plate bending. Commun. Numer. Methods Eng. 1993, 9, 53-63.

16. Kasparek, E.M. An efficient triangular plate element with C1-continuity. Int. J. Numer. Methods Eng. 2008, 73, 1010-1026. [CrossRef]

17. Chen, W.J.; Cheung, Y.K. Refined 9-Dof triangular Mindlin plate elements. Int. J. Numer. Methods Eng. 2001, 51, $1259-1281$.

18. Hughes, T.; Taylor, R.; Kanoknukulchai, W. A simple and efficient finite element for plate bending. Int. J. Numer. Methods Eng. 1977, 11, 1529-1543. [CrossRef]

19. Reissner, E. The effect of transverse shear deformation on the bending of elastic plates. J. Appl. Mech. 1945, 12, 69-77. [CrossRef]

20. Mindlin, R.D. Influence of rotatory inertia and shear on flexural motions of isotropic elastic plates. J. Appl. Mech. 1951, 18, 31-38. [CrossRef]

21. Senjanović, I.; Vladimir, N.; Hadžić, N. Modified Mindlin plate theory and shear locking-free finite element formulation. Mech. Res. Commun. 2014, 55, 95-104. [CrossRef] 
22. Zienkiewicz, O.C.; Taylor, R.L.; Too, J.M. Reduced integration technique in general analysis of plates and shells. Int. J. Numer. Methods Eng. 1971, 3, 275-290. [CrossRef]

23. Pugh, E.D.; Hinton, E.; Zienkiewicz, O.C. A study of triangular plate bending element with reduced integration. Int. J. Numer. Methods Eng. 1978, 12, 1059-1078. [CrossRef]

24. Malkus, D.S.; Hughes, T.J.R. Mixed finite element methods-reduced and selective integration techniques: A unification of concepts. Comput. Method. Appl. Mech. Eng. 1978, 15, 63-81. [CrossRef]

25. Hughes, T.J.R.; Cohen, M.; Haroun, M. Reduced and selective integration techniques in finite element analysis of plates. Nucl. Eng. Des. 1978, 46, 203-222. [CrossRef]

26. Bathe, K.J.; Dvorkin, E.N. A four-node plate bending element based on Mindlin/Reissner plate theory and a mixed interpolation. Int. J. Numer. Methods Eng. 1985, 21, 367-383. [CrossRef]

27. Nguyen, X.H.; Rabczuk, T.; Stephane, B.; Debongnie, J.F. A smoothed finite element method for plate analysis. Comput. Method. Appl. Mech. Eng. 2008, 197, 1184-1203. [CrossRef]

28. Lee, S.W.; Pian, T.H.H. Improvement of plate and shell finite elements by mixed formulation. AIAA J. 1978, 16, 29-34. [CrossRef]

29. Katili, I. A new discrete Kirchhoff-Mindlin element based on Mindlin-Reissner plate theory and assumed shear strain fields-Part I: An extended DKT element for thick-plate bending analysis. Int. J. Numer. Methods Eng. 1993, 36, 1859-1883. [CrossRef]

30. Brasile, S. An isostatic assumed stress triangular element for the Reissner-Mindlin plate-bending problem. Int. J. Numer. Meth. Eng. 2008, 74, 971-995. [CrossRef]

31. Batoz, J.L.; Katili, I. On a simple triangular Reissner/Mindlin plate element based on incompatible modes and discrete constraints. Int. J. Numer. Methods Eng. 1992, 35, 1603-1632. [CrossRef]

32. Batoz, J.L.; Lardeur, P. A discrete shear triangular nine d.o.f. element for the analysis of thick to very thin plates. Int. J. Numer. Methods Eng. 1989, 29, 533-560. [CrossRef] 